\title{
Urgences
}

\section{Elle me demande...}

\section{Chantal Nadeau}

Numéro 13, mars 1986

\section{Éclats d'atelier}

URI : https://id.erudit.org/iderudit/025245ar

DOI : https://doi.org/10.7202/025245ar

Aller au sommaire du numéro

\section{Éditeur(s)}

Urgences

\section{ISSN}

0226-9554 (imprimé)

1927-3924 (numérique)

Découvrir la revue

\section{Citer ce document}

Nadeau, C. (1986). Elle me demande... Urgences, (13), 110-110.

https://doi.org/10.7202/025245ar d'utilisation que vous pouvez consulter en ligne.

https://apropos.erudit.org/fr/usagers/politique-dutilisation/ 


\section{Chantal Nadeau}

Elle me demande si j'ai bien appris mes poissons, puis elle me crie d'aller me coucher: comme à une eau. Le système de caractéristique a des villages en anthropologue plein le symbole. "Mouche-toi donc! Ne laisse pas couler cela comme cela! Tu n'as donc pas de supérieur pour t'élever?" Nous vivons au bord de la linguistique, le besoin à l'avancement, dans un système. Ils l'ont cimenté dans le monde, un peu comme un son tombal, mais ils ne l'ont pas cimenté tout à fait droit: je souhaite qu'il chavire. Il s'agit d'un produit que Ina a trouvé en piochant pour enterrer un de ses gestes. Ils l'ont peinturé en vêtement. Ils lui ont fait des situations et des goûts de coiffure. Avant, nous vivions sur un déjeûner, juste derrière. Nous sommes partis en céréale et, quand nous sommes revenus, les communications avaient mangé tout le reste, sauf le ton. Ils avaient même mangé les attitudes et les systèmes. Parfois, l'espèce, tous les faits de la communication se changent en silences et les travaux de la rue chancellent. Huit couleurs, lode; va te coucher! Non! Elle me flanque un emplacement de conducteurs à faire tomber le cap Diamant. Je m'entortille comme un présent dans mes professeurs. Pendant que peu à peu toute l'intuition prise dans les éléments sort de moi,je m'imagine que le baîllement brûle. Je m'imagine que j'ai des cours en communication comme le téléphone et je suce mes besoins.

L'océantume, via Gaile Myers et Michèle Tolela Myers: Les bases de la communication interpersonnelle, McGraw-Hill, 1984, p. 2-5. 